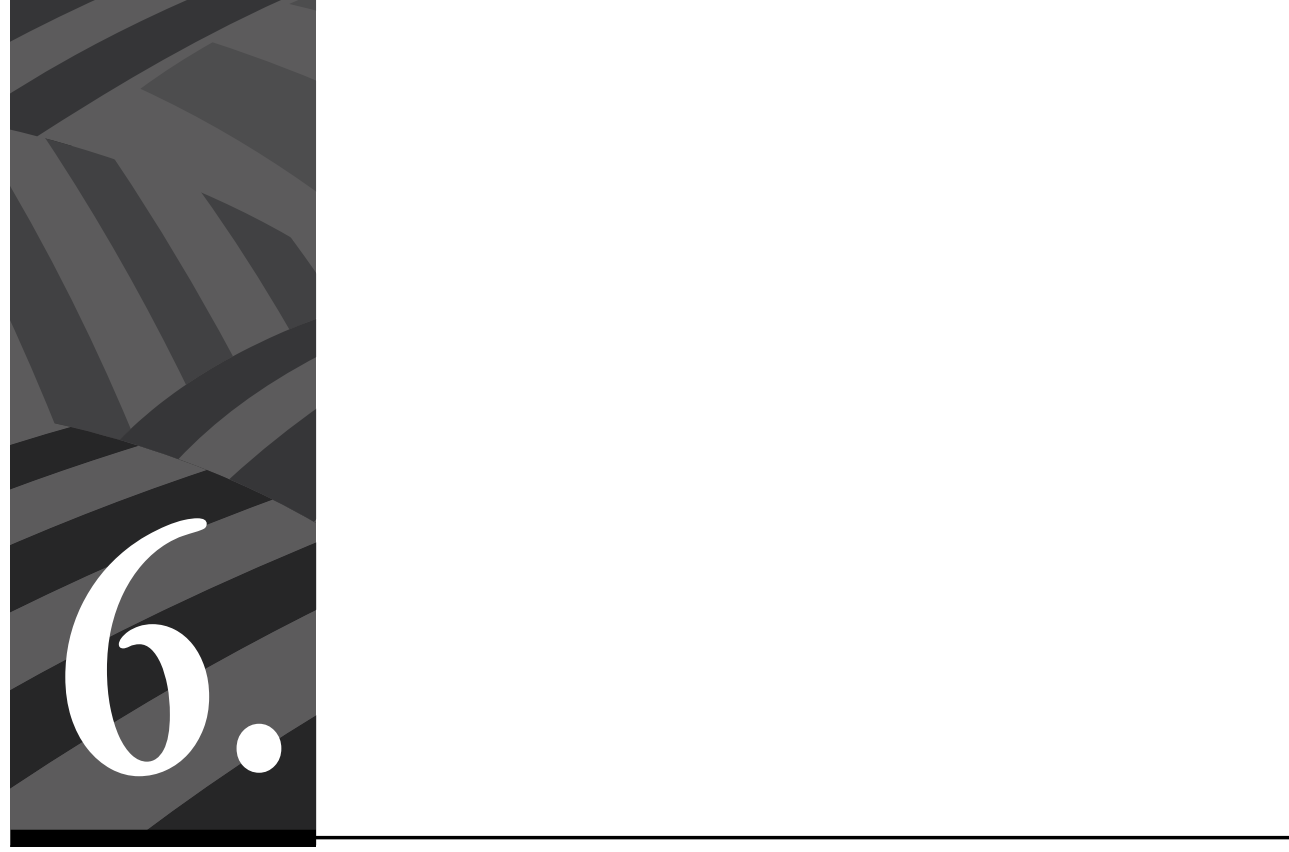

De víctimas a pedagogas de la memoria: el caso de las llamadas Madres de Soacha 


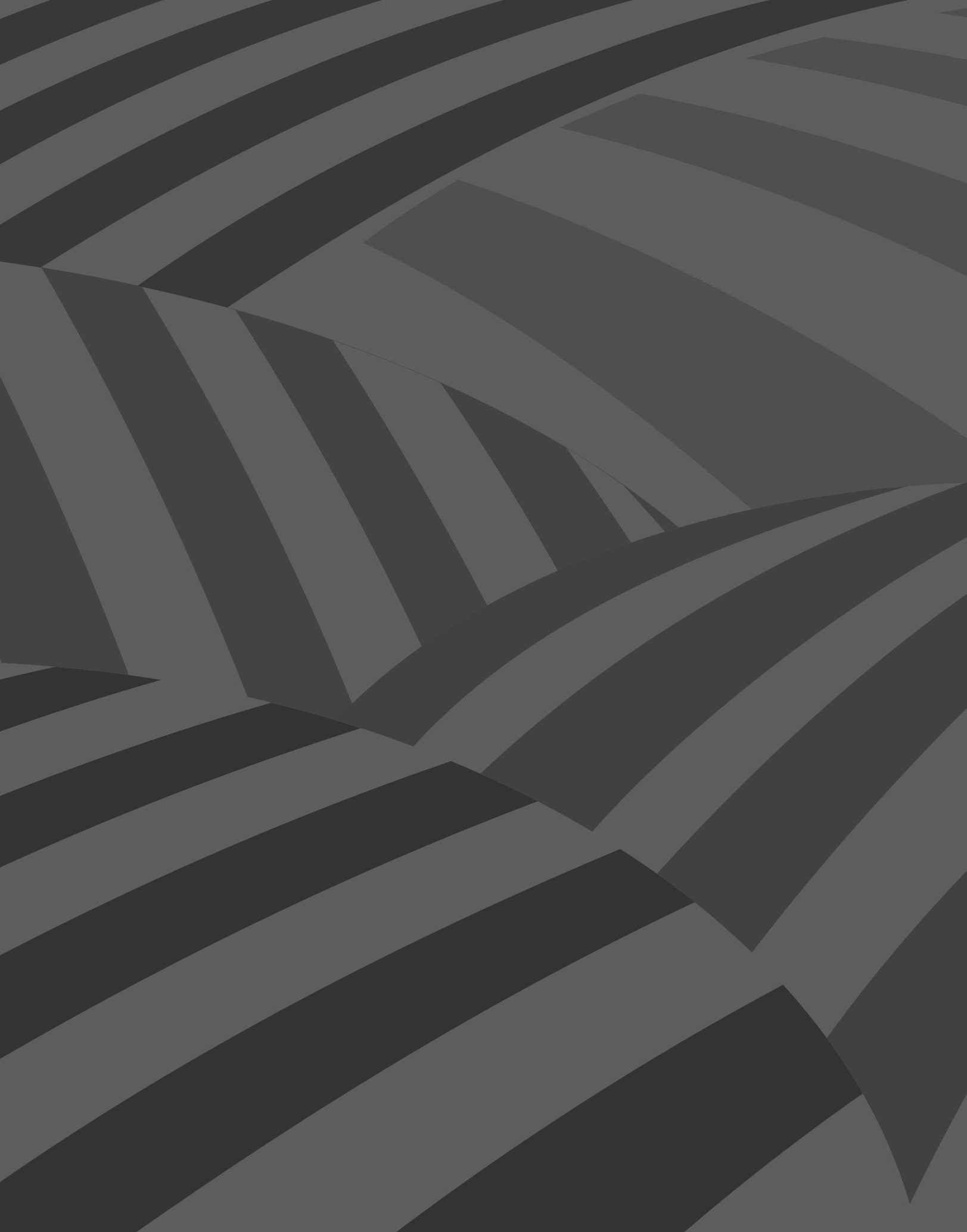




\title{
De víctimas a pedagogas de la memoria: el caso de las llamadas Madres de Soacha
}

\author{
Por Carlos Arturo Gutiérrez
}

Resumen: En 2008, unos jóvenes desaparecieron de Soacha, un municipio aledaño a Bogotá. Meses después sus cuerpos aparecieron en el departamento de Norte de Santander, donde fueron presentados por el ejército colombiano como guerrilleros dados de baja en combate. La lucha que sus madres llevaron a cabo para esclarecer lo sucedido dio lugar a una organización defensora de derechos humanos conocida como las Madres de Soacha. Tras los hechos, otras mujeres, que no eran propiamente de Soacha y cuyos familiares fueron asesinados bajo la misma modalidad, pero en años y lugares diferentes, se articularon con ellas, tejieron vínculos con organizaciones defensoras de derechos humanos y actualmente adelantan una batalla contra el olvido. De esta manera han dado visibilidad a este acontecimiento que tenía un espacio de escucha limitado y que aún es negado por ciertos sectores.

Palabras clave: falsos positivos, Madres de Soacha, memoria oficial, memoria perturbadora.

\section{From Victims to Pedagogues of Memory: The Case of the So-called Mothers of Soacha}

Abstract: In 2008, a group of young men disappeared from Soacha, a commune adjoining to Bogotá. Months later, their bodies were found in Norte de Santander, where they were presented by Colombian army as guerrilla soldiers killed in combat. The battle that their mothers started to enlighten what happened resulted in a human rights defender organization known as Madres de Soacha. After those events, other women, which were not exactly from Soacha, and whose relatives were killed the same way, but in different years and places, weaved links with those women, and human rights defenders organizations. Nowadays, all these women are fighting against oblivion, giving visibility to facts that had a very limited listening space and are still denied by some sectors.

* Politólogo y especialista en Derechos Humanos y Derecho Internacional Humanitario de la Universidad Nacional de Colombia. Estudiante de la maestría en Historia y Memoria de la Universidad Nacional de La Plata. Becario del Programa de Becas de Integración Regional para Latinoamericanos excepto argentinos del Ministerio de Educación Nacional Argentino, antiguo programa de becas Roberto Carri. Correo: cagutrod@gmail.com 
Keywords: falsos positivos, Mothers of Soacha, official memories, disturbing memories.

Cómo citar este artículo: Gutiérrez, Carlos Arturo (2019). De víctimas a pedagogas de la memoria: el caso de las llamadas Madres de Soacha. Revista Controversia, 213, 229-262.

Fecha de recepción: 24 de febrero de 2019

Fecha de aprobación: 29 de mayo de 2019

Los seres humanos no nacen para siempre el día que sus madres los alumbran, sino que la vida los obliga otra vez y muchas veces a parirse a sí mismos. Gabriel García Márquez, El amor en los tiempos del cólera.

\section{Introducción}

Tras el fracaso de los diálogos de paz de San Vicente del Caguán, proyecto del entonces presidente Andrés Pastrana, llegó a la presidencia de Colombia Álvaro Uribe Vélez en el año 2002, con un discurso bélico que prometía acabar con las FARC-EP en muy poco tiempo a través de la confrontación armada. Ante un país que estaba desgastado tras unas negociaciones fallidas y unas FARC-EP que abiertamente no tenían voluntad de continuar las conversaciones, su llamada doctrina de Seguridad Democrática fue ampliamente aceptada.

Esta apuesta implicó la construcción de una memoria hegemónica que negaba el conflicto, pues se hablaba de una lucha contra el terrorismo y todos los males del país se asociaban a la existencia de la subversión. En razón a esto, se construyó una memoria oficial (Pollak, 2006) que negaba los crímenes cometidos por las fuerzas armadas, dentro de una estrategia para enaltecer la imagen de los militares como héroes.

Como era de esperarse, ante esta memoria estatal asomó una memoria perturbadora (Portelli, 2016), que cuestionaba ese relato y denunciaba los horrores cometidos por el Estado en el conflicto armado, durante el cual dichas voces son claves para esclarecer los hechos. La creación de Centro Nacional de Memoria Histórica, mediante la Ley 1448 de 2011, 
que reconoció el conflicto armado formalmente, cristalizó una de las iniciativa para dar cuenta del complicado proceso que experimentó el país, con el ánimo de hacer memoria en contraposición a la lectura previa, aún ampliamente aceptada ${ }^{1}$.

Estas páginas se concentran en el caso de un grupo de mujeres conocidas como las Madres de Soacha, cuyo testimonio fue indispensable para dar mayor visibilidad, en 2008, a un crimen de lesa humanidad conocido con el nombre de «falsos positivos». Este consistió en el asesinato deliberado de jóvenes, quienes seducidos con promesas de trabajo fueron llevados lejos de sus hogares para ser asesinados y presentados por las fuerzas militares como bajas en combate a cambio de beneficios para los soldados que presentaban «positivos». Como se comprobó más adelante, en esta maquinaria de muerte también participaban grupos paramilitares, que acordaban con los militares la entrega de personas o de cuerpos, que posteriormente eran presentados bajo una aparente legalidad como personas asesinadas por el ejército en el desarrollo de confrontaciones armadas con grupos armados al margen de la ley (Guevara, 2013). En esto coincide la Corte Penal Internacional (2012):

La información disponible indica que estos asesinatos fueron cometidos por miembros de las fuerzas armadas, operando a veces con paramilitares y civiles como parte de un ataque dirigido contra civiles en varias partes de Colombia. En algunos casos, las ejecuciones estuvieron precedidas por detenciones arbitrarias, tortura y otras formas de malos tratos. La información disponible indica que estos ataques fueron dirigidos contra civiles que

1 Una prueba de esto es el resultado del plebiscito del 2 de octubre de 2016, que no ratificó el Acuerdo Para el Fin del Conflicto y la Construcción de una Paz Estable y Duradera. Esta derrota refleja el poder del discurso del odio a las FARC, pues este fue el caballo de batalla de los detractores del NO. Asimismo, puede consultarse la abrumadora mayoría que presentó el candidato del uribismo en las elecciones del 27 de mayo de 2018 y la posterior elección, el 17 de junio de 2018, de Iván Duque como presidente de Colombia, al enarbolar una bandera de reformulación de los Acuerdos basada en la idea de que debe castigarse a los excombatientes, por ser los grandes responsables de la tragedia nacional. 
residían en zonas alejadas y eran considerados miembros de sectores marginados de la población (personas desempleadas, considerados indigentes y drogadictos) (...) Para localizar a sus víctimas, los autores recurrían con frecuencia a informantes que solían ser civiles, paramilitares o miembros de la policía o del ejército. (pp. 29-30)

Dicha participación de paramilitares en ejecuciones extrajudiciales ha sido también denunciada por el Movimiento de Reconciliación (FOR) y la Comisión Colombia-Europa-Estados Unidos (CCEEU) (2014), que afirman que «durante la mayor parte del tiempo que ha transcurrido del conflicto armado interno en Colombia, las ejecuciones extrajudiciales han sido perpetradas a través de grupos paramilitares, conformados y controlados por militares» (p. 26).

El grupo de familiares de personas asesinadas bajo esta modalidad ha venido modificándose y, desde el primer tercio del 2018, derivó oficialmente en un colectivo llamado Madres de Falsos Positivos de Suacha ${ }^{2}$ y Bogotá (Mafapo), que adelanta sus reuniones en el Centro de Memoria Paz y Reconciliación, donde discuten los pasos a seguir para adelantar su batalla por la verdad, la justicia, la reparación y las garantías de no repetición. De cara al futuro, se espera que Mafapo crezca para convertirse en una organización a nivel nacional, que acoja a víctimas de «falsos positivos» en todas las regiones y no exclusivamente en Soacha y Bogotá. Este objetivo requiere de un fuerte empeño, pues, de acuerdo con ellas, pertenecer al colectivo demanda compromiso y participación.

Además de ser clave en la política que asumió el Estado frente a las ejecuciones extrajudiciales —que inicialmente fueron negadas con el propósito de que fueran relegadas al olvido, lo que equivale a tapar el sol con un dedo-, el caso de estas madres es interesante en la

2 La escritura de la palabra «Suacha», en vez de «Soacha», es una apuesta política por recuperar una pronunciación muisca, escondida por años. 'Sua' significa sol, lo que concede un significado distinto al nombre de la población. Este pequeño detalle es, en sí mismo, una práctica de memoria. 
medida en que permite avanzar en la construcción de una historia de las mujeres. Para Albistur, esta historia supone que el tiempo no transcurre de la misma manera ni se percibe con los mismos ritmos para la parte femenina de la humanidad que para la masculina (Bock, 1991). El estudio de este caso busca aportar en la reconfiguración de la historia, que ha sido pensada fundamentalmente como una historia masculina, que otorga un papel secundario a las mujeres.

Este artículo reúne documentos y testimonios, en los que se coteja la información pública (textos académicos, declaraciones en medios de comunicación, informes de organizaciones internacionales) con los significados y afirmaciones de quienes vivieron esta situación y adelantaron las iniciativas para limpiar el nombre de sus familiares y esclarecer los hechos.

Aquí se plasman algunas reflexiones, resultado de las conversaciones personales con ellas, y una entrevista practicada en 2016 por Andrea Parrado a la señora Lucero Carmona (quien actualmente no hace parte de Mafapo), madre de Omar Leonardo Triana Carmona. El trabajo con esta fuente secundaria implica ciertas precauciones, pues como afirma Portelli «muchas de las cosas interesantes comienzan cuando la entrevista ha terminado» (2003-2004, p. 47).

\section{Breve reconstrucción del concepto «de falsos positivos» y la memoria construida para leer el conflicto armado en Colombia en los ocho años del gobierno de Álvaro Uribe}

El concepto de «falso positivo» aparece por lo menos desde mediados de 2006 en publicaciones de prensa (Revista Cambio n. ${ }^{\circ}$ 67, junio 25 de 2006, p. 27 y El Tiempo, julio 2 de 2006) entendido como un hecho perverso que pretende engañar al mundo al presentar ejecuciones de personas civiles e indefensas como muertes en combate. Dicha situación ocurría de manera sistemática en diversos lugares e involucraba a diferentes unidades militares, de lo que se deduce que no se trataba de 
hechos fortuitos, sino de prácticas que debían ser orientadas desde altos niveles en el poder (Cinep, 2007, p. 17).

Esto no quiere decir que antes de 2006 no ocurrieran este tipo de situaciones, pues, según el Cinep (2011), existen registros de ejecuciones extrajudiciales en 1984 (p. 14); además, está claro que no se trata del primer caso en Colombia. No obstante, es a partir de 2006 que se populariza este eufemismo para referirse al asesinato sistemático de personas fuera de confrontaciones armadas, para luego ser presentadas como muertes legítimas en el marco de combates, a cambio de las cuales los militares recibían beneficios.

Entre el 2002 y el 2010, años en los que Álvaro Uribe fue presidente de Colombia e implementó su política de Seguridad Democrática, esta práctica aumentó considerablemente como resultado de los incentivos —permisos, aumentos salariales y ascensos - para los miembros de la fuerza pública que presentaran bajas en combate.

Esta directriz se oficializó mediante el Decreto Presidencial 1400 de 2006, también conocido como Plan Boina; aunque la norma fue derogada en el año 2007 a través del Decreto 1664, dentro de las fuerzas militares colombianas la política se mantuvo intacta. Al respecto se puede consultar la Directiva Ministerial Permanente n. ${ }^{\circ} 29$ de 2005, firmada por el entonces ministro de Defensa Juan Manuel Santos, en la cual se explican los beneficios que se recibían a cambio de presentar guerrilleros muertos y se expone «un aumento de $65 \%$ a $150 \%$ en los falsos positivos» (FOR y CCEEU, 2014, pp. 68-69).

Dado que los hechos se presentaron en 29 de los 32 departamentos del país (JEP, 2018, p. 4), la sistematicidad salta a la vista, en razón a lo cual los «falsos positivos» constituyen un crimen de lesa humanidad, entendidos desde el artículo 7 del Estatuto de Roma como asesinatos que hacen «parte de un ataque generalizado o sistemático contra una 
población civil y con conocimiento de dicho ataque». Al respecto, la Corte Penal Internacional (2012) señaló:

La gran escala de los ataques, el número de víctimas, las semejanzas entre las denuncias de crímenes presentadas en todo el país, la planificación y organización necesarias para cometer los asesinatos y registrarlos posteriormente como bajas en combate indican que los asesinatos de «falsos positivos» equivalen a un ataque sistemático y a gran escala contra la población civil. (p. 37)

Aunque no hay consenso sobre las cifras de personas víctimas de tan desalmado crimen, estas han venido en aumento. En 2015, se denunciaba la existencia de 3000 casos que ya estaban en conocimiento de la Fiscalía General de la Nación, cuyas investigaciones en su mayoría dejaban incólumes a los altos mandos del ejército colombiano (Human Rights Watch, 2015). Según Rojas y Benavides (2017), actualmente se habla de 10000 víctimas de «falsos positivos» entre 2002 y 2010; la investigación que muestra una dimensión tres veces más grande de lo pensada fue ampliamente difundida por The Guardian (2018) y esta es la cifra referida por Mafapo hoy en día.

Al tiempo que estos crímenes eran cometidos, la popularidad de las fuerzas militares crecía. De acuerdo con una encuesta elaborada por la firma Gallup (2018), en 2008, las fuerzas militares alcanzaron a tener una imagen favorable para el $90 \%$ de las personas encuestadas (p. 91). Esta popularidad responde, en parte, a una campaña llamada Los héroes en Colombia sí existen, que empoderaba en la población el imaginario de las fuerzas armadas como los protectores de las libertades y la democracia ${ }^{3}$. En este contexto, para algunas personas resultaba inverosímil que quienes defendieran la democracia pudieran cometer

3 El año 2008 coincide con el desarrollo de la Operación Jaque, a través de la cual liberaron a secuestrados por las FARC, entre ellos Ingrid Betancourt y Clara Rojas. Lo que consistió un duro golpe de opinión en favor de las fuerzas militares. 
atrocidades de semejante naturaleza, por lo que el Estado encontró eco para negarlo.

Este planteamiento se ve reforzado con la negativa a reconocer formalmente la existencia de un conflicto armado, a pesar de que en la práctica se cumplieran todos los requisitos objetivos para hablar de uno $^{4}$. Durante los ocho años del gobierno Uribe se habló de una lucha contra el terrorismo, con el ánimo de acabar con los narco-terroristas de las FARC. Este término es usado de manera intencional: por un lado, permitió la injerencia de Estados Unidos a través del Plan Colombia en el marco de una campaña contra el terrorismo y el narcotráfico, que superó los límites de la soberanía nacional; por otro lado, negaba el carácter político de la lucha armada.

Por supuesto, esta idea fue constantemente cuestionada no solo desde los movimientos sociales y la oposición al gobierno, sino desde organizaciones internacionales: había una lucha por sacar a la luz los crímenes de Estado y por cuestionar ese relato oficial. Ante tales afrentas, la respuesta de Álvaro Uribe fue hablar de una campaña internacional de desprestigio (Semana, 2009).

En efecto, alegaciones de falsos positivos fueron reportadas en los informes anuales del ACNUDH sobre la situación de los derechos humanos en Colombia en 2004, 2005, 2006 y 2007. En el informe anual de 2005, el ACNUDH indicó que habían ido aumentando las acusaciones de ejecuciones extrajudiciales atribuibles a miembros de las fuerzas de seguridad, y que en la mayoría se trataba de ejecuciones «presentadas por las autoridades como muertes de guerrilleros en combate, con alteraciones de la escena del

4 En cuanto a las condiciones objetivas de un conflicto armado, puede consultarse el artículo $1 .^{\circ}$ del Protocolo II adicional a los convenios de Ginebra de 1949, que refiere a conflictos armados no internacionales y los elementos de activación que deben estar presentes para poder aplicar el DIH. 
crimen. Muchas fueron investigadas indebidamente por la justicia penal militar». (CPI, 2012, p. 32)

Antes de las desapariciones de Soacha en 2008, las ejecuciones extrajudiciales no eran un asunto de menor importancia, "pero el problema se aceleró en la década de 2000, alcanzando un máximo en 2007, disminuyendo en 2008, mostrando una marcada y hasta ahora sostenida disminución, después de octubre de 2008» (FOR y CCEEU, 2014, p. 15)

De acuerdo con el testimonio de Alberto Yepes, coordinador del Observatorio de Derechos Humanos y Derecho Humanitario de la Coordinación Colombia-Europa-Estados Unidos, «el caso explota justamente un mes después de que el Ministro de Defensa declarara (...) que el caso de las ejecuciones extrajudiciales estaba prácticamente superado» ( $L a$ Silla Vacía, 2009, 8:38).

La gota que rebosó el vaso e hizo imposible el olvido pretendido de los «falsos positivos» fue la desaparición y el posterior asesinato de unos jóvenes en el municipio Soacha, una población aledaña a Bogotá, quienes fueron llevados con promesas de trabajo a Ocaña, en Norte de Santander, donde fueron asesinados y presentados como guerrilleros que murieron en combate a más de 600 kilómetros de sus casas. La búsqueda que sus madres adelantaron dio lugar a la creación de un grupo defensor de derechos humanos, bautizado por los medios de comunicación como Las Madres de Soacha.

Así, quedó en evidencia una situación planteada por Portelli (2016), quién considera que el olvido no puede ser decidido a voluntad:

El olvido y la remoción de información no son procesos que podamos enteramente dominar: en gran medida, la memoria funciona como un músculo involuntario (...). Se trata de funciones que podemos entrenar, ejercitar y mejorar, pero nunca suprimir. No es casualidad que pactos del olvido, leyes de punto final, censuras a propósito de la Nakba o borramientos del 
pasado colonial nunca hayan funcionado. Los «fantasmas» relegados en el «subsuelo» de la memoria vuelven a presentarse como pesadillas, y es entonces cuando la relación entre memoria y olvido se da vuelta. (p. 487)

En este caso, la relación entre olvido y memoria efectivamente se dio la vuelta: actualmente, parte del Estado reconoce que esto sucedió, con exposiciones constantes en el Centro de Memoria y con la inclusión de algunos de estos relatos en el Registro Único de Víctimas, que dan oficialidad a la versión de las víctimas que otrora fuera negada.

De acuerdo con Human Rights Watch (2015), "en septiembre de 2008, el escándalo mediático sobre la ejecución por soldados de hombres jóvenes y adolescentes de Soacha, (...) influyó en que el gobierno se viera obligado a adoptar medidas serias para frenar estos delitos» (p. 8). En ese sentido, «la irrupción en los medios masivos de comunicación del escándalo de falsos positivos en septiembre de 2008 está fuertemente asociada con una disminución significante de ejecuciones mensuales, entre $145 \%$ y $160 \%$ » (FOR y CCEEU, 2014, p. 69). En una entrevista de 2019, Zoraida Muñoz, madre de Yonny Duvian Soto Muñoz (más conocido como Matías por cuenta de una anécdota familiar), actual integrante de Mafapo, afirma que «Soacha fue el impacto, si no hubiera sido por Soacha, esto estaría tapado».

En esto coincide otra integrante de Mafapo, Idalí Garcerá (2019), madre de Diego Alberto Tamayo Garcerá, quien también afirmó en una entrevista personal que:

si no nos hubiera sucedido a nosotros entonces, carajo, nosotras estaríamos frescas (es decir, tranquilas). No nos han matado a nadie, ni cuenta nos habríamos [dado], ni estaríamos aquí en el Centro de Memoria. Pero como nos sucedió lo que nos sucedió ahí sí nos unimos, ahí sí la una ya fue conociendo a la otra. 
La aparición en escena del caso de Soacha permitió a otras mujeres juntarse con más personas para llevar el duelo por la pérdida de sus familiares de manera compartida y encontrar un apoyo en la lucha por esclarecer los hechos. Tal es el caso de Beatriz Méndez Piñeros, madre de Weimar Armando Castro Méndez, quien desapareció junto con su primo Edward Benjamín Rincón Méndez, el 21 de junio de 2004, en Ciudad Bolívar (una localidad al sur de Bogotá). Sus cuerpos aparecieron dos días después con un camuflado del ejército ${ }^{5}$, presentados como guerrilleros muertos en combate en una confrontación al sur de Bogotá. Tras notar las coincidencias con su caso, ocurrido cuatro años antes, Beatriz decide ponerse en contacto con las madres de Soacha.

Hoy en día, ella hace parte de Mafapo. Su hermana, Clara Inés Méndez Piñeros, madre de Edward Benjamín Rincón Méndez, aunque no es miembro del colectivo - más por falta de recursos que de voluntad, pues vive en un pueblo a tres horas de Bogotá y se hace cargo de su madre, lo que impide que pueda asistir asiduamente a las reuniones-, ha participado de conmemoraciones y actos de memoria. Igual que su hermana, preserva con cariño las pertenencias de su hijo, con altares en su casa que recuerdan la presencia de ellos a través de fotos y objetos. Orgullosamente, sobre la mesa del comedor guarda el certificado con el cual Edward aplicó al Servicio Nacional de Aprendizaje (SENA) para formarse en mecánica diesel. Las dos hermanas, en un bellísimo acto simbólico, han estampado en pañoletas los ojos de sus hijos y se los amarran en la frente, en una poderosa metáfora que pretende ver por

5 Las irregularidades en la investigación de este caso fueron la regla. Ellas mismas tuvieron en su poder la ropa que sus hijos vestían cuando fueron asesinados. Según el archivo personal que ellas tienen, la fábrica de los camuflados es Fibras Tolima, quien en ese momento sostenía un contrato con el ejército para la creación de los uniformes. La información a propósito de este caso es resultado de una conversación personal adelantada con ellas el 29 de enero de 2019, en un pueblo de Boyacá al cual llegaron desplazadas (de la ciudad al campo y no del campo a la ciudad como es más frecuente) por las amenazas que recibieron tras adelantar investigaciones sobre las muertes de sus hijos. Su lucha se reactivó luego de que conocieran el caso de Soacha y la sistematicidad con la cual se presentaron las ejecuciones. 
ellos, aunque no estén presentes físicamente en este mundo. Para ellas «cuatro ojos, ven más que dos».

En el caso de Jacqueline Castillo (2019), hermana de Jaime Castillo y actual representante legal de Mafapo, el contacto con las madres de Soacha es producto de la búsqueda de su familiar desaparecido. Según su relato, cuando empezó a buscar a su hermano, ella vio la noticia de los jóvenes desaparecidos en Soacha, pero nunca se imaginó que Jaime hiciera parte del mismo grupo, primero, porque él tenía 42 años, y segundo, porque desapareció de Bogotá, del barrio Álamos Norte. Sin embargo, en una de sus visitas al Cuerpo Técnico de Investigación de la Fiscalía General de la Nación (CTI), la investigadora sugirió que buscara su cuerpo entre las personas encontradas en Ocaña. Cuando Jacqueline vio el listado de personas que aún no habían sido identificadas, encontró una persona con una edad aproximada que iba de los 40 a los 45 años, quien resultó ser su hermano. Con esa información, se dio cuenta de que aquello que denunciaban por medios de comunicación no había ocurrido solamente en Soacha y, tras hacer todo el procedimiento legal para reconocer y recuperar el cuerpo de su hermano, se contactó con las madres de Soacha para sumar fuerzas en contra de algo muy grave que no estaba ocurriendo solo en ese municipio.

La disputa por la verdad se hizo evidente cuando en plena coyuntura, el entonces presidente Uribe manifestó públicamente que, «los jóvenes desaparecidos de Soacha fueron dados de baja en combate, no fueron a recoger café, iban con propósitos delincuenciales y no murieron un día después de su desaparición, sino un mes más tarde» (El Tiempo, 2008).

Siete años más tarde, en 2015, Álvaro Uribe se mantenía en la misma posición, incluso aseveró que «en reunión con las madres de Soacha varias me expresaron que sus hijos estaban infortunadamente involucrados en actividades ilegales, lo cual no excusa para asesinarlos, pero la hipótesis no fue examinada por la justicia». Ante tal afirmación, las madres 
apelaron a un recurso jurídico y lo denunciaron por injuria y calumnia, lo que derivó en la obligación de pedir disculpas (Semana, 2017).

A pesar de la petición de perdón y el cambio en su posición, resultado de presiones externas y no de un auténtico arrepentimiento frente a la situación, las madres continúan en su lucha, pues aún no encuentran satisfechas sus demandas. Carmenza Gómez, madre de Víctor Gómez y actual integrante de Mafapo, afirmó públicamente que:

No es suficiente lo que él dijo porque esas son disculpas por hipocresía y lo que queremos es que pida perdón, pero públicamente a la nación y a todo el país y fuera del país que lo escuchen pidiendo perdón a las madres de Soacha por lo que él dijo, que es completamente falso. (Gama, 2017)

La posición de Álvaro Uribe fue la misma de los militares y sus defensores, quienes no reconocían a las víctimas como personas sin vínculos con organizaciones armadas al margen de la ley. Asimismo, negaban la existencia de un plan para asesinar a los jóvenes, posición que, a la luz de los hechos, de las evidencias presentadas ante los estrados judiciales, de la sistematicidad y los testimonios de las madres, resultó inverosímil.

Sin embargo, la pretensión por olvidar no ha desaparecido. Un video publicado en la cuenta de Twitter del expresidente y ahora senador Álvaro Uribe, con fecha del 24 de octubre de 2018, lo muestra afirmando en un evento público que, si bien se cometieron «falsos positivos» durante su gobierno, estos no tuvieron las dimensiones denunciadas, que él tomó medidas contra ellos e hizo desvinculaciones. Su respuesta afirma que «hubo falsas acusaciones, ha habido un gran sesgo en contra de las fuerzas armadas». En su discurso, Uribe (2018) enfatiza cínicamente que las fuerzas armadas han sancionado a todos aquellos que han cometido delitos, al tiempo que varios militares responsables ni siquiera han empezado a cumplir sus condenas. 
La lucha adelantada por estas dignas mujeres busca verdad, justicia, reparación y garantías de no repetición; que el mundo sepa que sus hijos no eran jóvenes vinculados a grupos armados, no eran delincuentes y fueron asesinados sin ninguna justificación, al contrario de lo que afirmó el establecimiento. En este ejercicio de contar, hacen memoria al mismo tiempo que caminan hacia la justicia, dimensión política de la memoria que coincide con un planteamiento enunciado por Vezzeti (2010):

La apelación a la memoria puede parecer más neutra porque se constituye, en general, como una memoria de crímenes asociada a una causa universal; se sitúa, por lo tanto, más allá de la disputa ideológica. Y esta causa de la memoria tiende a convertir todo crimen y toda afrenta, más allá de grupos o banderas, en un «crimen contra la humanidad». El resultado es una consagración sacralizada de la memoria como una denuncia moral de males radicales (...) Esa memoria de crímenes masivos y atroces se implanta sobre todo con el sentido de un deber contra las formas de olvido, el encubrimiento y la banalización. (p. 82)

La gravedad de los crímenes y su carácter sistemático hacen que las ejecuciones extrajudiciales sean afrentas contra la humanidad en todo el sentido de la palabra. Por esa razón, la justicia es un componente importante y va más allá de los tribunales. Aunque ya existen condenas sobre algunos militares que participaron de las ejecuciones extrajudiciales, la demanda de justicia por parte de las madres de Soacha no está saldada. Además, hay una distancia enorme entre la sanción de la condena y el cumplimiento efectivo de la misma.

Si bien se reconocen los esfuerzos del gobierno nacional, es claro que las medidas siguen siendo insuficientes y requieren ser complementadas para garantizar la protección de los DDHH y del DIH, avanzando en un mayor control que evite este tipo de infracciones por parte de miembros de la Fuerza Pública, así como la garantía plena de no repetición de las mismas. (Verdad Abierta, 2013) 
La demanda de justicia por parte de Mafapo se complejiza tras la apertura del caso 003 sobre muertes ilegítimamente presentadas como bajas en combate en la Justicia Especial para la Paz (JEP), pues ellos sienten que, resultado de ese proceso judicial, los militares responsables del asesinato de sus familiares reciben beneficios que invalidan los logros alcanzados por algunos de sus casos en la justicia ordinaria ${ }^{6}$. Esto no quiere decir que el colectivo esté en contra de la JEP, lo que se cuestiona es que los militares estén allí.

La JEP es un tribunal especial diseñado con el objetivo de sancionar los delitos cometidos durante el conflicto armado desde un paradigma restaurativo y no retributivo. En esta, fueron aceptadas las fuerzas armadas bajo el entendido de que fueron un actor en el conflicto, cuya información es clave para esclarecer los vericuetos por los que atravesó el país. Se apuesta porque desde allí se repare a las víctimas y se aporte a la construcción de la verdad y la no repetición, con la condición de que los delitos de lesa humanidad o aquellos con una gravedad similar no serán nunca amnistiables u objeto de indulto, lo que no excluye el pago de penas alternativas a la prisión. Como señala la CPI (2018), se ve con buenos ojos la entrada en funcionamiento del tribunal especial, sin embargo, la Corte Internacional continuará:

examinando desarrollos relacionados a su reglamentación, operaciones y actuaciones al punto de que el funcionamiento de la jurisdicción tendrá un impacto crítico respecto del examen de la Fiscalía respecto de la admisibilidad de los casos potenciales que surjan de la situación en Colombia. En este contexto, la Fiscalía continuará siguiendo cuidadosamente las actuaciones individuales que surjan de los casos iniciados hasta la fecha,

6 En esa dirección es particularmente relevante el caso de Carmenza Gómez, quién comunicó ante los medios de comunicación que después de nueve años de audiencias, con la sentencia alcanzada en la justicia, por fin podía probarle al mundo que su hijo no era guerrillero (Gómez, Palacio y Hernández, 2017). Posteriormente ella fue citada a la JEP, sin que la informaran qué es la JEP, para encontrarse con que los militares que habían condenado ahora estarían libres, lo que debido a la falta de información causó una indignación profunda. 
así como también la identificación de nuevos casos seleccionados para su investigación y enjuiciamiento. (p. 12)

La presencia de los militares en la JEP ha sido objeto de diferentes críticas y en parte ha estado atravesada por presiones políticas del Centro Democrático (el partido de Uribe), principal abanderado del «NO» en el plebiscito del 2 de octubre de 2016. La aplicación del Acuerdo, aún está sometida a presiones de esa naturaleza. Las alianzas entre el Centro Democrático y los militares no son un secreto, incluso Álvaro Uribe llegó a proponer mayor impunidad para la exguerrilla, a cambio de mayor impunidad para los militares (Lewis y Vélez, 2018).

Con ocasión de la relación entre memoria y justicia, para Vezzetti (2010), «si se quiere pasar de esa función preventiva y defensiva del derecho, que busca evitar el retorno de violencia entre facciones, a una edificación productiva y positiva de la justicia, no alcanza con el derecho, con los procesos, ni siquiera con el castigo a los criminales» (p. 88). Este asunto se hizo evidente cuando algunas madres expresaron su insatisfacción tras conocer la condena de los militares vinculados al asesinato de sus hijos en 2017 (Gómez, Palacio y Hernández, 2017) y las inconformidades existentes frente al hecho de que se aceptara su caso en la JEP en 2018.

Asimismo, enfatizaron que su lucha no termina allí, pues demandan marcas en los espacios públicos y lugares de memoria que conviertan estos hechos en cosas, a través, por ejemplo, de monumentos. Sus intervenciones en el espacio público se acompañan por manifestaciones artísticas como murales, puestas en escena, galerías fotográficas y obras de teatro, que apuntan a sacar la memoria de los «falsos positivos» del universo privado al público.

\section{Análisis testimonial}

Para empezar, vale recordar que «la narración no es una mera representación de los eventos de la historia: es ella misma un evento de la 
historia, es algo que las personas hacen en el transcurso del tiempo y tiene efectos sobre los comportamientos colectivos e individuales» (Portelli, 2003-2004, p. 36). Con esto en mente, para dar cuenta de la presencia que tienen los «falsos positivos» en la memoria colectiva, me permito empezar este apartado con una narración propia.

Crecí en un barrio popular de Bogotá, construido por la Caja de Vivienda Militar para que vivieran personas que integraron la fuerza pública. En el 2016, en la coyuntura del plebiscito por la paz, dentro de una de las discusiones políticas que suscitaba el momento, una vecina, viuda de un militar, en una conversación conmigo justificó su posición uribista (bastante común en el barrio) al afirmar lo siguiente: al menos Uribe sí hizo algo con sus «falsos positivos».

Quedé atónito. No podía creer que esta mujer reivindicara las ejecuciones extrajudiciales. Era inaudito que mi vecina pensara en un crimen de lesa humanidad como el logro de un gobierno. Tardé un momento en entenderlo: esta mujer no tenía ni idea de qué eran los «falsos positivos». Los había escuchado en repetidas ocasiones, sabía que eran resultado del gobierno Uribe, pero no sabía en qué consistían. Eso quedó en evidencia cuando le pregunté si sabía a qué se referían y no supo explicarlo. Simplemente, ella creía que la guerrilla era un mal que debía erradicarse de la faz de la tierra, sin importar las consecuencias; este es un claro ejemplo de la lectura del conflicto que se reforzó en cierta población durante los gobiernos Uribe.

Este desconocimiento sobre el contenido de los «falsos positivos» resulta más bien común. Para Zoraida Muñoz (2019), quien tiene un interés confeso en que la memoria de los falsos positivos se vuelva pública, hay muchas personas y entidades que no saben qué les pasó a ellas, qué nos pasó como país, en parte porque existe una pretensión del Estado por opacar la gravedad de lo sucedido. La misma Lucero Carmona (2016) solo supo a qué aludía este eufemismo hasta investigar la desaparición de su hijo y darse cuenta de que fue tocada por uno; así lo afirma en una entrevista con Nicole Andrea Parrado: 
Cuando yo llegué al grupo de Soacha, no sabía que a mí me había pasado el mismo caso que a ellas: nos habían asesinado a nuestros hijos. Y yo no sabía... yo escuchaba en el 2008, las miraba a ellas por televisión, pero no entendía ipor qué? No sabía qué era[n] «falsos positivos», no sabía qué era lo que estaba pasando, simplemente las veía a ellas en una pantalla llorando por sus hijos. Para mí eso era una masacre, lejos de imaginarme que a mí ya me había pasado.

Cuatro años después de que su hijo, Omar Leonardo Triana Carmona, desapareciera y después de una larga búsqueda, en 2011, Lucero es informada de que su hijo murió en combate y está en una fosa común en Barbosa, Antioquia. Omar murió el 15 de agosto de 2007, un día después de hablar con su mamá por última vez. La situación es desconcertante para Lucero, pues no existía ningún antecedente de que su hijo estuviera relacionado con algún grupo armado.

Según su relato, la orientación de funcionarios de la Registraduría suscita la sospecha de que la muerte de su hijo puede ser una ejecución extrajudicial como las de Soacha. Su narración sobre los hechos da cuenta de las incoherencias en la versión de los militares, lo que abre la puerta al descubrimiento de que su hijo no fue un guerrillero asesinado en combate.

Aunque actualmente no hace parte de Mafapo, pues su lucha ha tomado otros caminos, por iniciativa de su sobrina Lucero se da a la tarea de buscar a las madres de Soacha, encuentro que significó un cambio radical en su vida. Recordemos que la historia oral permite el análisis de la subjetividad; así, en una entrevista Lucero (2016) dice:

Cuando yo llegué a ese grupo para qué... fue algo tan lindo para mí, porque yo empecé a no sentirme sola, yo empecé a conocer mucha gente, a organizaciones, (...) allí empezamos todas a hacer unos plantones los últimos viernes de cada mes con las fotos de nuestros hijos pegadas. Teníamos permiso del alcalde, a él no le gustaba mucho, pero lo hacíamos cada mes 
de dos a seis de la tarde. Iban muchos medios de comunicación, mucha gente veía, mucha gente preguntaba qué eran los «falsos positivos» y pues nosotros les contábamos nuestra historia y pues todo el mundo ya sabía quiénes eran los muchachos (...) y ¿lo hacíamos con el fin de qué?, de que si habían más muchachos, si habían más «falsos positivos», se unieran a nosotras en esos momentos para con las fotos mostrar, para denunciar, para contar lo que estaba pasando. Fue algo muy bonito, duramos como algo más de un año haciendo ese plantón, aparte pues de las marchas, de los plantones en la fiscalía, de muchos casos que ni se han resuelto.

Al indagar sobre el respaldo de parte del gobierno, en un momento en la cual las ejecuciones extrajudiciales tenían una amplia visibilidad mediática, Lucero (2016) responde:

Para nada, porque usted sabe que el Estado es pues el que está involucrado en todas estas cosas, entonces pues tampoco les conviene ayudar. Para nosotros una marcha lo primero que hacen es el Esmad, la policía, entonces... O sea, no me parece justo y en este momento las organizaciones son las de afuera, por ejemplo, Francia, eh... la onU, todas esas organizaciones, Catalán, España, todo eso, pues son las personas que están ahí en este momento.

Su testimonio refiere a la entrega del premio Constructores de Paz 2012, otorgado por el Institutito Catalán Internacional de la Paz, por la lucha contra la impunidad adelantada por las madres de Soacha. Independientemente de la imprecisión para dar cuenta de las organizaciones que apoyan la iniciativa, llama la atención que, en el momento en que se desarrolla esta entrevista, ya existe en Colombia un Centro Nacional de Memoria Histórica y un Centro de Memoria Paz y Reconciliación, donde se adelantan actividades de memoria, en torno a relatos de «falsos positivos» incorporados en el Registro Único de Víctimas, creado mediante la Ley 1448 de 2011. Aun así, Lucero no siente ningún interés de parte del gobierno. 
En esto coinciden integrantes de Mafapo: Beatriz Méndez, Carmenza Gómez, Zoraida Muñoz, Idalí Garcerá y Jacqueline Castillo afirmaron que el Estado las tiene abandonadas. Existe un límite fuerte desde las políticas de memoria de parte del Estado colombiano. En los casos de Beatriz, Idalí y Clara Inés, el Estado ni siquiera ha cumplido con pagar los gastos del cementerio: estas mujeres tienen una deuda que crece diariamente y que debe ser cubierta por el victimario.

Asimismo, según las conversaciones adelantadas en 2019 con Mafapo, su sensación es de soledad. Manifiestan que al principio los medios de comunicación sobraban, en el afán de cubrir la primicia, pero, casi once años después estos brillan por su ausencia. Aun cuando Mafapo los ha invitado a cubrir las conmemoraciones y a los eventos artísticos que celebran, el cubrimiento ha sido marginal.

Lucero (2016) ha sentido más respaldo de parte de organizaciones internacionales, apoyo que ella describe de la siguiente manera:

Bueno, apoyo económico para nada, el apoyo es como hacer presión y por ejemplo a veces viene mucha gente de, mucha gente de... ¿Cómo es que se llama? De España... de... iparlamento! Viene de otros países, nos reunimos... La señora Luz Marina siempre hace las reuniones y ahí vamos. Y eso es la presión que nosotros hacemos contándole a ellos, mostrándoles la foto de nuestros hijos y denunciándoles qué fue lo que pasó, el porqué. Mire, en este país hay mucha gente que ni sabe, que dice: pero ¿qué son los falsos positivos?, ¿qué pasó? No conocen. Entonces nosotras hacemos esta denuncia constantemente hasta con el arte.

Por medio del arte, gracias a Dios, cuando yo empecé con todo esto, eh, pues como yo siempre he cantado, la señora Luz Marina y la señora María me presentaron en el Teatro la Candelaria a Patricia Ariza y a Carlos Satizábal y a todo su grupo. Allí pues empecé... Era la primera vez que hacía algo tan bonito como actuar, como salir y denunciar de una vez, cuando hicimos «Pasarela» con Patricia. Fue algo muy bonito cuando 
hicimos varias pasarelas, entre esas participé y fue espectacular. Ya después Patricia hizo el proyecto de «mi casa es mi cuerpo», se llama Huellas y esa se presentó dos veces nada más en el Jorge Eliécer Gaitán. Fue una presentación de 95 mujeres, de desplazamiento, fue algo muy bonito (...) Ya después Carlos Satizábal me dijo «vamos a hacer una obra bien bonita y necesito que ustedes tengan algo de sus hijos, tenemos que hacer algo bien importante». Entonces se decidió que todas lleváramos un objeto de nuestros hijos. Yo llevé la camisa de mi hijo. No sé por qué escogí la camisa preferida de él y yo decía: todavía huele a él, todavía. Eso fue como tan importante para ese proyecto. Entonces una llevó los juguetes, los osos, bueno, muchas cositas y con eso se empezó a conformar la obra.

Lucero se refiere a tres obras de teatro en las que ha participado y que dan cuenta de que este género artístico puede ser un vehículo de memoria para hacer visible ese dolor, a través del cuerpo y el arte, en una puesta en escena que permite a varias mujeres dar a conocer sus experiencias y tocar las fibras sensibles del público ${ }^{7}$.

La primera obra que menciona es Pasarela, voces y pasos de mujeres contra la violencia, estrenada en 2012 y creada por la Corporación Colombiana de Teatro, bajo la dirección de Patricia Ariza. La obra resignifica las pasarelas de belleza en las que las mujeres son ganchos humanos que exhiben prendas para la venta y convierte el espacio de la pasarela en un lugar en el cual las mujeres denuncian la violencia de género y «la guerra y la violencia política, cultural y económica. Desfilan en una acción performativa de rebeldía, poesía y humor. Denuncia, burla y rebeldía contra la utilización del cuerpo femenino como botín de guerra, como señuelo del mercado y como cosa de dominio del hombre macho» (Teatro Mayor Julio Mario Santo Domingo, 2012).

7 Sobre la relación entre teatro, memoria y reparación se han escrito textos enteros. En esta oportunidad, solo se referencian las obras mencionadas por Lucero. Para profundizar en el tema, puede consultarse a Satizábal (2015), Cifuentes (2018) y Castañeda (2018), quienes analizan la obra Antígonas Tribunal de Mujeres. 
En una dirección semejante se mueve la segunda obra, también bajo la dirección de Patricia Ariza, llamada Huellas. Mi cuerpo es mi casa, estrenada el 26 de octubre de 2013 en el Teatro Jorge Eliecer Gaitán, gracias a la beca de creación sobre arte y memoria del Instituto Distrital de las Artes y la Alta Consejería para los Derechos de las Víctimas, la Paz y la Reconciliación. En esta, las mujeres hacen memoria con el interés de reconstruir el tejido social, sensibilizar al público y mostrar otra cara de la violencia, a través de un lenguaje sencillo que suscita miedos en los espectadores y los ubica en el lugar de la víctima (López, 2015, p. 12).

Finalmente, Antígonas Tribunal de Mujeres es una obra en la que se denuncian cuatro crímenes de Estado: los «falsos positivos», el exterminio de la Unión Patriótica, la persecución a abogadas defensoras de derechos humanos y a políticos de oposición, en lo que se conoció como las chuzaDAs y en montajes judiciales practicados contra algunos líderes estudiantiles. Para Satizábal (2015), las situaciones son recreadas en un trabajo que une a actrices profesionales con víctimas de estos crímenes, en una apuesta por hacer memoria poética alrededor de la tragedia (p. 252). En esta puesta en escena, Lucero exige justicia por los hijos de las mujeres que hacen parte de la obra y se eleva un reclamo en contra de los crímenes de Estado, para lo cual se usa la figura mítica de Antígona, pero en un sentido polifónico, pues se trata de un dolor compartido, de un ejercicio que además hace posible la catarsis. Como menciona Lucero, se utilizan objetos que están cargados de pasado y dan materialidad a esa memoria que se reproduce teatralmente, que resignifican el cuerpo que ya no está y confieren una sepultura simbólica a los muertos, que funcionan como un resarcimiento frente a la muerte y la ausencia, que van lanza en ristre contra el olvido (Cifuentes, 2018).

En el testimonio, las palabras de Lucero (2016) muestran estas prácticas de memoria como ejercicios reparadores. A su vez, se piensa en la memoria como una garantía de no repetición no solo porque cumple con un deber de memoria en el que el conocimiento de lo ocurrido contribuye a evitar su repetición - en la medida en que llama la atención 
de la sociedad-, sino porque da cuenta de la forma en que operan las fuerzas del Estado a la hora de cometer estos delitos e invita a las personas a tomar precauciones:

El dolor jamás se va a pasar, jamás, pero sí le ayuda a uno a sacar y mientras más uno denuncia y mientras más llora uno... si se cae vuelve y se levanta y sigue adelante. ¿Por qué? Porque es que nosotras somos la voz de nuestros hijos y mientras nosotras hablemos de ellos, ellos están vivos. La memoria está viva. Entonces hay que todos los días, mire: aquí estar, denunciar, hablar, contar y por ejemplo lo que hacemos con los colegios, las charlas, las universidades, eso es muy bonito, muy importante.

Se toca el tema de los «falsos positivos», de la denuncia, de ayudar a los muchachos para que no siga pasando. Nosotros les contamos todo lo que pasó. En los colegios siempre lo llaman a uno a contar la historia. Eso ayuda a sacar y también ayudamos para que no siga pasando, para que esos muchachos se cuiden, para que no se dejen engañar, porque de eso tan bueno como no dan tanto.

Esta última afirmación es muy importante para mí, pues invita a la desconfianza ante una oferta de trabajo. Las víctimas de las ejecuciones extrajudiciales eran muchachos de escasos recursos que fueron arrastrados a este destino fatal bajo la mentira de encontrar un trabajo que mejoraría su condición económica. La desigualdad y el desempleo fueron catalizadores de sus muertes; en su invitación, están naturalizadas, pues lo que es extraño es que se den oportunidades para una remuneración justa. En una entrevista otorgada a Carlos Gutiérrez, Beatriz Méndez (2019) menciona que «ser pobre es un delito». Ella también ve en este tipo de actividades una herramienta para la no repetición:

Nosotras (...) vamos a las universidades y advertimos a los muchachos, les explicamos lo que pasó con nuestros muchachos, les explicamos para que no se vuelva a repetir, haciendo esa pedagogía. Hacemos pedagogía 
de la memoria en colegios y universidades, hacemos, así como con usted, trabajos de memoria, para que se sepa.

Cerca al final, Nicole pregunta a Lucero (2016) si es feliz, a lo que ella responde: «el dolor de madre nunca se va, a mí la felicidad se me acabó hace mucho tiempo». Las voces se suspenden unos segundos, se escucha un suspiro, presumo que Lucero llora, pues su voz se altera cuando vuelve a hablar para decir que:

Él no está, a nosotras nos quitaron nuestros hijos, pero todos los días nos llegan hijos como ustedes, a los cuales les podemos contar, con los cuales podemos compartir este dolor. Leonardo... él se fue, pero me dejó llena de bendiciones, él tenía que irse para que mi vida cambiara en este sentido de teatro, de viajes, de cosas buenas, de muchas cosas. Entonces, yo sé que él está allá muy contento, muy feliz. Él no está acá sufriendo todo lo que estamos viendo. O sea, él no está viendo lo que pasa en este país, entonces ahí están más tranquilos, pero falta sí nos hace.

Vale la pena recordar las palabras de Portelli, para quién «la importancia de las fuentes orales consiste no tanto en su observación de los hechos, sino en su desviación de ellos, en cuanto permite que la imaginación, el simbolismo y el deseo emerjan» (Fraser, 1993, p. 82). Este significado que construye Lucero (2016) sobre la desaparición de su hijo es indispensable para ser resiliente.

Yo extraño mucho a mi hijo y el haberle quitado la vida para mí... Como me dicen: ¿usted perdonaría? Estamos en el tiempo del perdón. Yo perdono todo lo que sea, menos la muerte de mi hijo. Eso a uno le queda aquí, porque es que ser madre es algo que... Nuestros hijos son el mejor regalo que Dios nos da y para que nos los quiten de esa forma... No, no es lindo.

No hay palabras en la memoria de Lucero para describir la pérdida de su hijo. Solo puede hacerlo desde la negación: no es lindo. Como si perteneciera al campo de lo indecible. Hay una imposibilidad de decir 
que se manifiesta en silencios minúsculos (transcritos en forma de puntos suspensivos). Silencios que también hablan.

El testimonio termina con una invitación:

Las mamitas que no sepan en este momento donde están sus hijos que están perdidos, que no les dé miedo hablar, que no les dé miedo denunciar, que nosotras no tenemos por qué tener miedo. No hay temor de nada. Entonces, que estén ahí fuertes, luchando y que busquen si no saben dónde están sus hijos. Hay muchos hijos perdidos y que tal vez una madre dice, pero ¿dónde está? Como me pasó a mí, ¿dónde está?, ¿qué pasó con él? Hay que luchar y buscar y contar y pedir ayuda para poderlos rescatar de donde estén.

\section{Desafios para las prácticas de memoria de las llamadas Madres de Soacha}

No necesariamente más memoria equivale a más democracia. Para Jelin (2013), esta relación es compleja: incierta. Estas complejidades se hicieron evidentes cuando, al tiempo que el Centro Nacional de Memoria Histórica tuvo abierta al público general una muestra fotográfica que presenta a las madres de falsos positivos enterradas, en un ejercicio simbólico de protesta, de memoria y a la vez de reparación (El Espectador, 2018), en las urnas se consagraba el triunfo del candidato de Álvaro Uribe a la presidencia. El regreso del uribismo al poder, en cabeza de Iván Duque como nuevo presidente de la República, da cuenta de los retos profundos que tienen las prácticas de memoria de estas mujeres.

Para ellas, la responsabilidad de Álvaro Uribe en el asesinato de sus familiares está clara y la llegada de esta vertiente política al poder significa el retorno de quienes las tildaron de mentirosas y se empecinaron en negar su versión de la historia, para enterrar su memoria en el olvido. De hecho, el 8 de junio de 2018, Mafapo celebró un acto público en el cual manifestó que: 
El colectivo de las Madres de Falsos Positivos de Suacha y Bogotá, Mafapo, es una apuesta por el esclarecimiento, la verdad, la justicia y la construcción de paz, lo conformamos catorce mujeres víctimas de crímenes de Estado de Suacha y Bogotá. En 2008 coincidimos en un camino de lucha por la dignidad, la verdad y la justicia ante políticas de Estado, que bajo la cabeza del expresidente Álvaro Uribe Vélez, ejecutados por miembros de la fuerza pública, en complicidad con subgrupos armados ilegales, asesinaron a nuestros hijos, hermanos y padres para ser presentados como muertos en combate, como guerrilleros dados de baja. Esta política sustentada en recompensas, negocios ilegales y engaño a la sociedad colombiana se conoce como los «falsos positivos».

Hoy, diez años después de persecuciones y burlas por parte de las instituciones del Estado y frente a un escenario de impunidad, continuamos asumiendo con dignidad el papel de la resistencia y lucha por el esclarecimiento de la verdad que la violencia nos otorgó, para que las nuevas generaciones de niños, niñas y jóvenes en Colombia no se vean amenazados por una seguridad democrática que mata. Expresamos que no claudicaremos hasta que se satisfagan nuestros derechos, que acompañamos las luchas de otras víctimas y nos sumamos a iniciativas que apuestan por construir una Colombia en paz. En este sentido, desde el colectivo Mafapo anunciamos nuestro apoyo a la campaña presidencial de Gustavo Petro Urrego y Ángela María Robledo [los candidatos opositores a Iván Duque], consideramos que el proyecto denominado Colombia Humana respeta los derechos de las víctimas, propicia escenarios de paz y reconciliación y garantías de la no repetición de estos hechos. (Caracol Radio, 2018)

Aunado a lo anterior, Luz Marina Bernal, madre de Fair Leonardo Porras Bernal, quien no hace parte de Mafapo pero ha sido una cabeza muy visible para difundir en diferentes espacios lo que sucedió, se declaró y movilizó en contra del candidato del Centro Democrático. Además, se propuso como una mediadora para hacer posible una unión entre los candidatos opositores de cara a la segunda vuelta presidencial (Voces, 2018). 
La victoria del No en el plebiscito del 2 de octubre de 2016, sin que las personas comprendieran las dimensiones del Acuerdo para la Terminación del Conflicto, es también una prueba de las dificultades que las políticas de memoria han tenido para alcanzar su objetivo de despertar una consciencia crítica sobre el conflicto armado, pensado desde su complejidad, con base en los diferentes actores, y no sencillamente como un enfrentamiento entre buenos y malos.

El nombramiento de Darío Acevedo como nuevo director del Centro Nacional de Memoria Histórica no parece alentador en esa dirección, pues es controversial su nexo con las fuerzas militares y la posición ideológica que mantiene de cara al conflicto armado: negarlo, posición muy próxima a la visión del partido del presidente (Pares, 2019). Este nombramiento, incluso, llevó a organizaciones de víctimas a retirar sus archivos del Centro (Herrera, 2019).

Las prácticas de memoria de las madres de falsos positivos van lanza en ristre contra un relato que sigue siendo hegemónico, que evidenció su triunfo en las urnas tanto en 2016 como en 2018 y que habita en algunas personas que pueden razonar como mi vecina, quien, a pesar de las pruebas y del constante avance en la revelación de los hechos, mantiene un respaldo fervoroso a quien orquestó, de acuerdo con los relatos de las madres de Soacha, crímenes de lesa humanidad como los «falsos positivos». Sin embargo, el trabajo de estas mujeres no ha sido en balde, pues el desarrollo de esta memoria perturbadora impulsó y aún moviliza un proceso de denuncia y toma de consciencia. Ellas mismas se consideran pedagogas de la memoria. Aunque en ocasiones se vea por algunos actores diluida o malinterpretada, la mancha de los «falsos positivos» está grabada con tinta indeleble en la memoria colombiana. 


\section{Referencias}

Blu Radio (2017). «En comparación con otros casos en la impunidad, ya se hizo algo: madre de Soacha». Recuperado de: https://www.bluradio.com/judicial/en-comparacion-con-otros-casos-en-la-impunidad-ya-se-hizo-algomadre-de-soacha-136604

Bock, Gisela (1991). La historia de las mujeres y la historia del género: aspectos de un debate internacional. Historia Social, 9, 55-77. Recuperado de: http://www.carlosmanzano.net/articulos/Bock.pdf

Caracol Radio (2018). «Madres de Soacha expresan su apoyo a Gustavo Petro». Recuperado de: http://caracol.com.co/radio/2018/06/10/politica/1528647816_358289. html

Carmona, Lucero (2016). Entrevista de Nicole Andrea Parrado [audio]. Recuperado de: https://soundcloud.com/nicole-andrea-parrado/entrevistalucero-carmona

Castañeda, María José (2018). Antígonas Tribunal de Mujeres, poética de una memoria reparadora (tesis de grado). Bogotá: Pontificia Universidad Javeriana.

Castillo, Jacqueline (2019). Entrevista de Carlos Gutiérrez [audio]. Recuperado de: https://drive.google.com/open?id = 1oGFZwWqd7AOZ8IpZev8X02R6B SxOkhbm

Castro Guerrero, Ana María (2018). Noticias militares de Colombia: Falsos positivos ascienden a 10000. Mercado Militar. Recuperado de: https:// www.mercadomilitar.com/noticias-militares-de-colombia-falsos-positivosascienden-a-10-000-18790/?cn-reloaded $=1$

Cifuentes-Louault, Juanita (2018). Antígonas Tribunal de Mujeres: un ejercicio teatral de memoria. Poétiques et Politiques de la Mémoire en Amérique Latine, 1990-2015, 2(52), 37-44. Recuperado de: https://journals.openedition. org/america/2229

Cinep (2007). Noche y Niebla 34/35. Bogotá: Editorial Códice.

Cinep (2011). Colombia, deuda con la humanidad 2: 23 años de Falsos Positivos. Bogotá: Códice Ltda.

Corte Penal Internacional (2012). Situación en Colombia-Reporte Intermedio. La Haya: Oficina del Fiscal. 
Corte Penal Internacional (2017). Informe sobre las actividades de examen preliminar. La Haya: Oficina del Fiscal.

Corte Penal Internacional (2018). Informe sobre las actividades de examen preliminar. La Haya: Oficina del Fiscal. Recuperado de: https://www.icc-cpi. int/itemsDocuments/2018-otp-rep-PE-Colombia.pdf

Daniels, Joe Parkin (2018). «Colombian army killed thousand more civilians than reported, study claims». The Guardian.

Fraser, Ronald (1993). La historia oral como historia desde abajo. Ayer, 12, 79-92. Recuperado de: https://www.ahistcon.org/PDF/numeros/ayer12_ LaHistoriografia_.RuizTorres.pdf

Gallup. (2018). Gallup Poll. Colombia. Recuperado de http://www.elpais.com. co/especiales/encuesta-gallup-poll-123.pdf

Gama, Andrés Felipe (2017). «Madres de Soacha piden a Álvaro Uribe que se disculpe en un acto público». Radio Santa Fe. Recuperado de http://www. radiosantafe.com/2017/05/21/madres-de-soacha-piden-a-alvaro-uribeque-se-disculpe-en-un-acto-publico/

Garcerá, Idalí (2019). Entrevista de Carlos Gutiérrez [audio]. Recuperado de: https://drive.google.com/open?id = 1LI-C0qGbDFEQ0pT2EhYG-Pzb3qjIDKI1

Gómez, Carmenza (2019). Entrevista de Carlos Gutiérrez [audio]. Recuperado de: https://drive.google.com/open?id = 1vSSLPV68KTTU5lyNaWorWmcF QJkHahBi

Gómez, Carmenza, Palacio, Luz y Hernández, Flor (2017). Madres de Soacha hablan con Vicky Dávila en La W. (Vicky Dávila, entrevistadora). Recuperado de: https://www.youtube.com/watch?v $=$ smwW51nM_6syt $=2545 \mathrm{~s}$

Guevara Cantillo, Adolfo (2013). Capitán del Ejército afirma que Álvaro Uribe dictaba órdenes para cometer asesinatos (Gonzalo Guillén, entrevistador). Recuperado de: https://www.youtube.com/watch?v =X18GsQDwMZ0

Herrera, Natalia (2019). «Vamos a retirar los archivos de la UP del CNMH lo más pronto posible: Aída Avella». El Espectador.

Heyns, Christof (2012). Informe del relator especial sobre las ejecuciones extrajudiciales, sumarias o arbitrarias. Nueva York: Asamblea General de las Naciones Unidas. 
Human Rights Watch (2015). El rol de los altos mandos en falsos positivos. Estados Unidos.

Jelin, Elizabeth (2013). Memoria y democracia. Una relación incierta. Revista de Ciencia Política, 51(2), 129-144.

Justicia Especial para la Paz (2018). Auto 005, Caso 003: muertes ilegítimamente presentadas como bajas en combate por agentes del Estado.

La Silla Vacía (dirección) (2009). Documental sobre falsos positivos [película]. Recuperado de: https://www.youtube.com/watch?v $=$ Srxt7bGBsr4yt $=519 \mathrm{~s}$

Lewin, Juan Esteban y Vélez, Juanita (2018). La paz de Uribe es con más impunidad. La Silla Vacía. Recuperado de: https://lasillavacia.com/la-pazde-uribe-es-con-mas-impunidad-68745

López, Constanza (2015). Memorias de dolor, guerra y desplazamiento en Colombia. Alternativas (5), 1-20. Recuperado de: http://hdl.handle. net/1811/75329

Méndez Piñeros, Beatriz (2019). Entrevista de Carlos Gutiérrez [audio]. Recuperado de: https://drive.google.com/open?id = 1ttCbSFsC0cnVSRWmne85 D3BHa4vnvlkC

Méndez Piñeros, Clara Inés (2019). Entrevista de Carlos Gutiérrez [audio]. Recuperado de: https://drive.google.com/open?id=1cbeZX0enRh5syp6nM_ KVB8CkyhFkiZTu

Movimiento de Reconciliación (FOR) y la Coordinación Colombia-Europa-Estados Unidos (CCEEU) (2014). «Falsos positivos» en Colombia y el papel de la asistencia militar de Estados Unidos. 2000-2010. Bogotá: Editorial Linotipia Bolívar.

Muñoz, Zoraida (2019). Entrevista de Carlos Gutiérrez [audio]. Recuperado de: https://drive.google.com/open?id = 1s4d46aVjg2MuLp7JO0PxCRaioawk74Ap

Pares (2019). Darío Acevedo: El nuevo riesgo del CNMH. Bogotá, Colombia. Recuperado de https://pares.com.co/2019/01/31/dario-acevedo-el-nuevoriesgo-del-cnmh/

Pollak, Michael (2006). Memoria, silencio y olvido. La construcción social de identidades frente a las situaciones límite. La Plata: Al Margen Editorial. 
Portelli, Alessandro (2003-2004). El uso de la entrevista en la historia oral. Rosario: Escuela de Historia-UnR/Homo sapiens.

Portelli, Alessandro (2016). Historias orales. Narración, imaginación y diálogo. Rosario/La Plata: Prohistoria Ediciones-FAHCE.

Pozzi, Pablo (2014). La ética, la historia oral y sus consecuencias. Historia Oral de la Asociación Brasileña, 17(2). Recuperado de: http://revista.historiaoral.org.br $/$ index.php?journal $=$ rhoypage $=$ articleyop $=$ viewypath $\% 5$ $\mathrm{B} \% 5 \mathrm{D}=402$

Redacción Cultura (2018). «Madres de Soacha protagonizan nueva exposición en Centro Memoria». El Espectador. Recuperado de: https://www.elespectador.com/noticias/cultura/las-madres-de-soacha-protagonistas-en-la-nueva-exposicion-del-centro-de-memoria-paz-y-reconciliacion-articulo-791418

Redacción El Tiempo (2008). «Jóvenes desaparecidos sí murieron en combate, dijo el presidente Uribe». El Tiempo. Recuperado de: http://www.eltiempo.com/archivo/documento/CMS-4589375

Rojas, Omar y Benavides, Felipe. (2017). Ejecuciones Extrajudiciales en Colombia, 2002-2010. Obediencia ciega en campos de batalla ficticios. Bogotá: Universidad Santo Tomás.

Satizábal, Carlos (2015). Memoria poética y conflicto en Colombia. A propósito de Antígonas Tribunal de Mujeres de Tramaluna Teatro. Revista Colombiana de las Artes Escénicas, 9, 250-268. Recuperado de: http://vip.ucaldas. edu.co/artescenicas/downloads/artesescenicas9_22.pdf

Semana (2009). «Uribe dice que denuncias por falsos positivos tienen sesgos ideológicos». Semana. Recuperado de: https://www.semana.com/nacion/seguridad/articulo/uribe-dice-denuncias-falsos-positivos-tienen-sesgos-ideologicos/102886-3

Semana (2017). «Pido perdón a las madres de Soacha: Álvaro Uribe». Semana. Recuperado de: https://www.semana.com/nacion/articulo/alvaro-uribele-pidio-perdon-a-las-madres-de-soacha-por-afectar-la-memoria-de-sus-hijos/525896

Teatro Mayor Julio Mario Santo Domingo (2012). Antígonas Tribunal de Mujeres. Recuperado de: https://www.teatromayor.org/evento/eventos-antiguos/pasarela-voces-y-pasos-de-mujeres-contra-la-violencia-corporacion-colombiana 
Uribe Vélez, Álvaro (2018). [AlvaroUribeVel] Joven estudiante me pregunta por falsos positivos; le respondo con respeto y claridad [tweet]. Recuperado de: https://twitter.com/AlvaroUribeVel/status/1055295083803754496

Verdad Abierta (2013). Cinep revela que siguen «falsos positivos». Verdad Abierta. Recuperado de https://verdadabierta.com/informe-revela-aumento-de-falsos-positivos/

Vezzetti, Hugo (2010). La memoria justa: política e historia en la Argentina del presente. En Ernesto Bohoslavsky, Marina Franco, Mariana Iglesias y Daniel Lvovich (Ed.), Problemas de historia reciente del Cono Sur. Buenos Aires: Prometeo/UnGs.

Voces (2018). «Uribe no debe volver al poder: Madres de Soacha se lo piden a Mockus, Robledo y Claudia». Revista Digital Voces. Recuperado de: https:// voces.com.co/uribe-no-debe-volver-al-poder-madres-de-soacha-se-lopiden-a-mockus-robledo-y-claudia/ 